Note

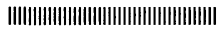

\title{
Imaging Plate as a Dosimeter for Estimating Ambient Dose Equivalent of Scattered Radiations in a Diagnostic X-ray Room ${ }^{\dagger}$
}

\author{
Hiroko Ohuchi, Norimichi Juto ${ }^{*}$, Toshimitsu $\mathrm{S}_{\mathrm{ATOH}}{ }^{* *}$, Yoichi EGUCHI ${ }^{* *}$ and Mamoru B ABA $^{* * *}$ \\ Graduate School of Pharmaceutical Sciences, Tohoku University \\ ***Cyclotron and Radioisotope Center, Tohoku University \\ 6-3 Aoba, Aramaki, Aoba-ku, Sendai-shi, Miyagi Pref. 980-8578, Japan \\ ${ }^{*}$ Chiyoda Technol Corporation \\ 1-7-12 Yushima, Bunkyo-ku, Tokyo 113-8681, Japan \\ **Yamagata University Hospital \\ 2-2-2 Iidanishi, Yamagata-shi, Yamagata Pref. 990-9585, Japan
}

Received February 21, 2006

\begin{abstract}
A method using BAS-MS type imaging plates (IPs) has been developed to estimate the values of ambient dose equivalent of scattered photon radiations in a diagnostic $X$-ray room where interventional cardiology procedures are frequently performed. An IP made of europium-doped $\mathrm{BaFBr}$, a photostimulated luminescence material, is a highly sensitive two-dimensional radiation sensor. IP can be used as a passive dosemeter for a specific period, combined with a post-irradiation annealing procedure. The detector response to $X$-rays with effective energies between 30 and $120 \mathrm{keV}$ were investigated via measurements with and without the use of metal filters (aluminum, copper, and cadmium) of varying thicknesses. The ambient dose equivalent can be evaluated by using a flat energy response to the dose equivalent obtained by taking the weighted sum of the sensitivity data measured under three different metal filters, without requiring knowledge of the effective energies of scattered photon radiations.

The value of ambient dose equivalent at several measuring points in a diagnostic X-ray room was evaluated for periods of either 2 or 4 weeks using the flat ambient dose equivalent response and the annealing procedure. This method using IPs is practical for estimating values of ambient dose equivalent in a diagnostic Xray room.
\end{abstract}

Key Words : imaging plate, scattered radiation, X-ray, interventional radiology

\section{Introduction}

Interventional radiology (IR) offers an oppor-

† IVR 室内散乱 X 線の空間線量測定へのイメージン グプレートの応用。

大内浩子, 寿藤紀道 ${ }^{*}$, 佐藤俊光 ${ }^{* *}$, 江口陽一**, 馬場 護 $* * *$ : 東北大学大学院薬学研究科, $* * *$ 東 北大学サイクロトロン・ラジオアイソトープセンター, 980-8578, 宮城県仙台市青葉区荒巻字青葉 6-3,

*千代田テクノル株式会社，113-8681，東京都文京 区湯島 1-7-12，**山形大学医学部附属病院，9909585 , 山形県山形市飯田西 2-2-2。 tunity to treat a greater range of pathologies in more patients and at lower cost than conventional radiography. This imaging modality thus reduces the need for expensive operating suites and extended hospital in-patient admissions ${ }^{1}$. While the use of IR has greatly increased in recent years, reports of radiationinduced injuries to patients' skin have steadily increased since the early $1990 \mathrm{~s}^{2), 3)}$. Patients are not the only individuals at risk. IR is a procedure in which staff can be exposed to a signifi- 
cant risk of occupational radiation. Staff doses correlate with patient doses, in that higher patient doses result in an increased amount of scattered radiations in the intervention suite. There are significant contributions to the photon scatter from materials in the suite other than within the patient. Doses to staff such as radiologists, nurses, and radiological technologists might largely vary according to not only the nature of the work, but also their physical positions during the procedure. Estimating the ambient dose equivalent $H^{*}(10)$ in a diagnostic X-ray room where IR procedures are performed should be important to prevent staff overexposures.

In this study, a new method using BAS-MS type $\mathrm{BaFBr}: \mathrm{Eu}^{2+}$ imaging plates (IPs) has been developed to evaluate the value of the ambient dose equivalent of scattered radiations in a diagnostic X-ray room. An IP of europium-doped $\mathrm{BaFBr}$, a photostimulated luminescence material, is a highly sensitive two-dimensional radiation sensor. IP can be used as a passive dosimeter for a specific period, combined with an appropriate post-irradiation annealing procedure ${ }^{4) .5}$. IP's sensitivity greatly depends on the $\mathrm{X}$-ray energy, because the photostimulable phosphor is composed of elements having relatively high atomic numbers. The ambient dose equivalent can be evaluated using a response having a flat energy dependence by taking the weighted sum of the sensitivity data measured using different metal filters with different thicknesses. It does not require the knowledge of the effective energies of scattered radiations. An attempt was also made to estimate the values of $H^{*}(10)$ of scattered photons using IPs with several metal filters at several measuring points both inside and outside a representative diagnostic X-ray room, where interventional cardiology procedures are frequently performed.

\section{Materials and Method}

$2 \cdot 1$ Imaging plate and readout technique

The commercially available imaging plate, BAS-MS2025 $(20 \mathrm{~cm} \times 25 \mathrm{~cm})$, manufactured by Fuji Photo Film Co., Ltd., was used in this study. The imaging plate consists of a $9-\mu \mathrm{m}$ thick protective Mylar film and $115-\mu \mathrm{m}$-thick photostimulable phosphor $\left(\mathrm{BaFBr}: \mathrm{Eu}^{2+}\right)$ affixed to a $188-\mu \mathrm{m}$-thick plastic backing. The BAS-MS is waterproof. A $4.5 \mathrm{~cm} \times 4.5 \mathrm{~cm}$ piece of IP material was prepared as a single IP sheet by cutting each plate. The IP sheets were wrapped in black polyethylene to shield them from visible light during X-ray irradiation. The IP is reusable. Illuminating it with visible light for approximately 40 min erases any residual latent image caused by natural radiations and/or a previous X-ray irradiation experiment. The BAS-1000 readout system (Fuji Photo Film Co., Ltd.) of $200 \mu \mathrm{m} \times 200 \mu \mathrm{m}$ pixels is used to read the IP sheet. In the sensitive phosphor layer of an IP, ionizing radiation creates a large amount of trapped centers, which record information about the deposited energy and its position. Stimulating the IP optically with a He-Ne laser $(633 \mathrm{~nm})$ within the image reader provides the energy necessary to release the trapped charges and causes the occurrence of photo-stimulated luminescence (PSL) $(390 \mathrm{~nm})$ from the positions of the trapped centers. The luminescence is detected via a photomultiplier tube in the image reader. The information of the energy deposited at each position is acquired by the image reader and recorded as a digital signal. 


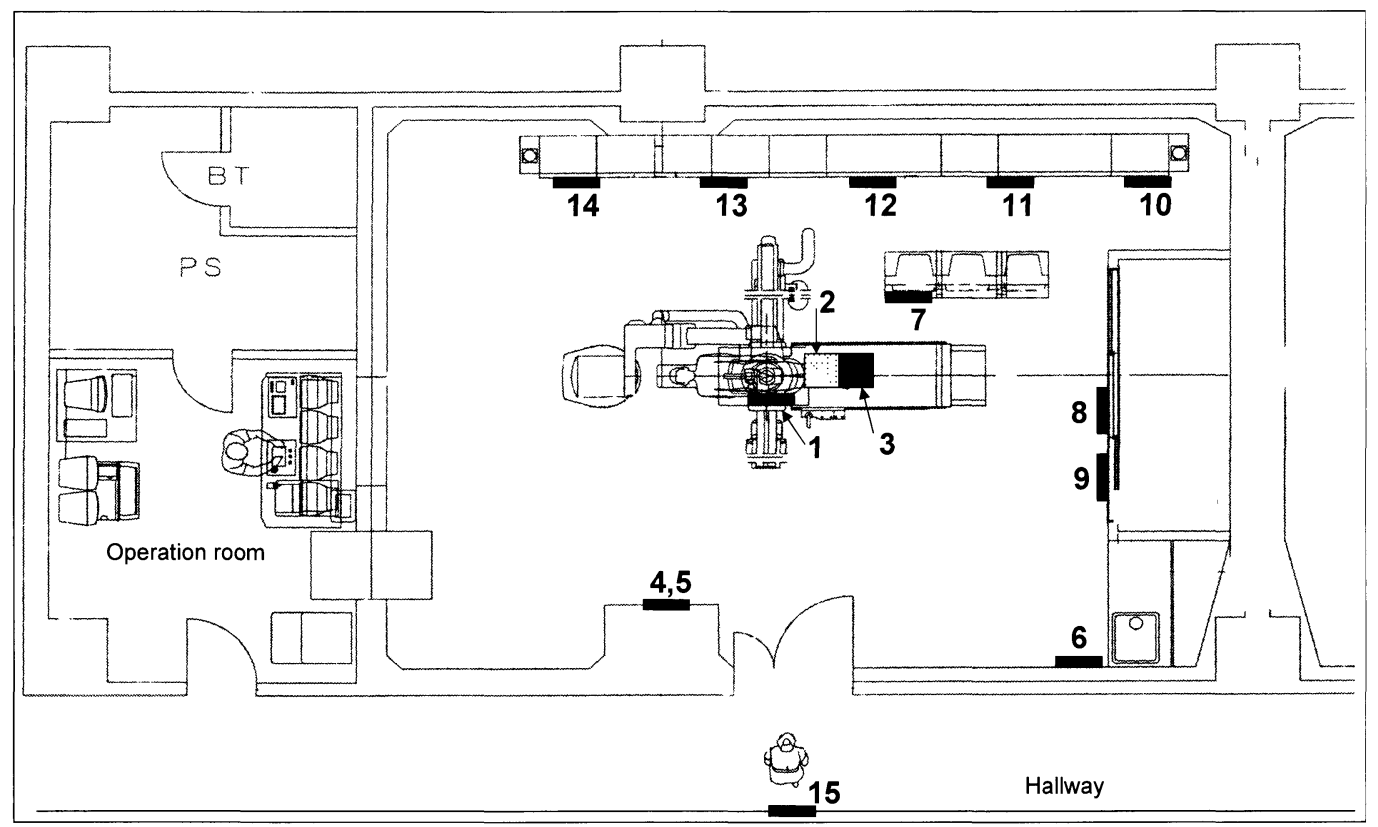

Fig. 1 Measurement points both inside and outside the diagnostic X-ray room.

\section{$2 \cdot 2$ X-ray irradiation}

The diagnostic X-ray room at Yamagata University Hospital, where interventional cardiology is frequently performed, is equipped with an X-ray generator, KXO-100G (Toshiba Medical Systems Corporation), provided with biplane positioners with frontal and lateral Carms. The procedures are performed with the X-ray tube under the examination couch. The filters for the X-ray generator were 1.1-mmthick Al plus 0.03-mm-thick Ta for fluoroscopy or 1.5-mm-thick $\mathrm{Al}$ for radiography. When the tube voltage was varied between 60 and 120 $\mathrm{kV}$, the effective energies, which were determined by measuring the half-value-layer using aluminium, varied between 34.2 and $46.9 \mathrm{keV}$ for fluoroscopy and 31.0 and $42.3 \mathrm{keV}$ for radiography, respectively.

To estimate the values of $H^{*}(10)$ of scattered radiations, the sets of filters comprising aluminum ( $\mathrm{Al})(Z=13)$ sheets $0.3,0.5$, and 1.0 $\mathrm{mm}$ in thickness, copper $(\mathrm{Cu})(Z=29)$ sheets
0.1 and $0.3 \mathrm{~mm}$ in thickness, and cadmium (Cd) $(Z=48)$ sheets 0.5 and $1.0 \mathrm{~mm}$ in thickness were attached to each surface of the plate. The sets of IPs with three metal filters and without a filter were placed at several points inside and outside the room as shown in Fig. 1 for 2 or 4 weeks.

Point 1 was on the surface of a lead shield, which hangs from the examination couch to protect a cardiologist's waist from exposure. The IP was placed on the outside of the shield. Point 2 was on the floor under the examination couch and point 3 was underneath the ceiling right above the examination couch. Points 4 and 5 were on the surface of the wall near the couch, $265 \mathrm{~cm}$ and $150 \mathrm{~cm}$, respectively, above the floor. Point 6 was on the surface of the wall in the corner of the room $150 \mathrm{~cm}$ above the floor, where nurses are often on standby. Point 7 was on the surface of a monitor screen 150 $\mathrm{cm}$ above the floor, which hangs from the ceiling. Points 8 to 14 were on each surface of the 
wall $150 \mathrm{~cm}$ above the floor inside the X-ray room. Point 15 was at the same height on the wall right in front of the door outside the room.

After irradiation, the IPs were collected, annealed at $80{ }^{\circ} \mathrm{C}$ for $24 \mathrm{~h}$ by keeping the IPs inside an incubator, MOV-112P2 (SANYO Electric Biomedical Co., Ltd.), then scanned with the BAS-1000 reader system. In the application of IP to dosimetry, the fading causes serious problems. The fading is considered to be caused by the recombination of holes and electrons shallowly trapped in the F centers, having several activation energies ${ }^{6}$. The post-irradiation annealing procedure can eliminate trapped charges with low activation energies and minimize the effect of fading, so that quantitative measurement of the radiation dose with high activation energies is possible ${ }^{4), 5}$. The practical optimum annealing condition for quantitative measurement for a month-long detector was determined to be the annealing of BAS-MS at $80{ }^{\circ} \mathrm{C}$ for $24 \mathrm{~h}^{\prime \prime}$. The same condition was used in this experiment.

\section{Calibration}

IP responses to X-rays in air with effective energies of $30,40,60,80$, and $120 \mathrm{keV}$ (the peak voltages were $37.6,50,75,100,150 \mathrm{kV}$, respectively), which covered the $\mathrm{X}$-ray energy range used in IR procedures, were investigated using the X-ray generator at the accredited laboratory of the Japan Quality Assurance Organization (JQA) in Tokyo, Japan. The effective energies were determined at JQA by measuring the half-value-layer using aluminium or copper. Two or four IPs were irradiated at each tube voltage at an air kerma value of $60 \mu \mathrm{Gy}$. The IPs with three metal filters and without a filter were placed $2 \mathrm{~m}$ from the X-ray target in the $\mathrm{X}$-ray generator. IP responses to ${ }^{137} \mathrm{Cs}$ gamma rays in air were investigated using a ${ }^{137} \mathrm{Cs}$ point source $\left(0.238 \mathrm{mGy} \mathrm{h}^{-1}\right.$ at $1 \mathrm{~m}$ on 11 December 2003 and gamma emission energy of 0.662 $\mathrm{MeV}$ ) at the Cyclotron and Radioisotope Center (CYRIC) of Tohoku University. Two filtered IP sets were irradiated at $60 \mu \mathrm{Gy}$, which was measured with an Exradin model A6 (Exradin, Inc.) $800 \mathrm{~mL}$ ionization chamber. The ionization chamber at CYRIC was traceable to the Japanese national standard maintained by the JQA. After irradiation, the IPs were left inside an incubator, EYELA, LTI-601SD（Tokyo Rikakikai Co., Ltd.) maintained at $15{ }^{\circ} \mathrm{C}$ for $24 \mathrm{~h}$ and then scanned using the BAS-1000 readout system.

The measured IP sensitivity with and without the aluminum, copper, and cadmium filters of various thicknesses is plotted against the effective X-ray energy in Figs. $2 a^{-}$c. All sensitivity data were normalized by the corresponding sensitivity data measured using ${ }^{137} \mathrm{Cs}$ gamma rays. The sensitivities measured without a filter had a peak at around $50 \mathrm{keV}$, caused by the $\mathrm{K}$ electron absorption of $\mathrm{Ba}$, and gradually decreased towards both lower and higher energies. Figure $2 \mathrm{a}$ shows that the sensitivities to low-energy X-rays $(<50 \mathrm{keV})$ decreased with increasing aluminum filter thickness, while the sensitivities to high-energy X-rays (>50 keV) were almost the same with and without an aluminum filter. This indicates that even the thickest aluminum filter absorbed almost none of the high-energy X-rays. Figures $2 b$ and 2c show that the IP sensitivities measured with the copper and cadmium filters decreased with increasing filter thickness over the entire range of effective X-ray energies. The decrease with cadmium filters was greater than with copper filters because of the higher atomic number of cadmium. 

equivalent of scattered radiations in a diagnostic X-ray room

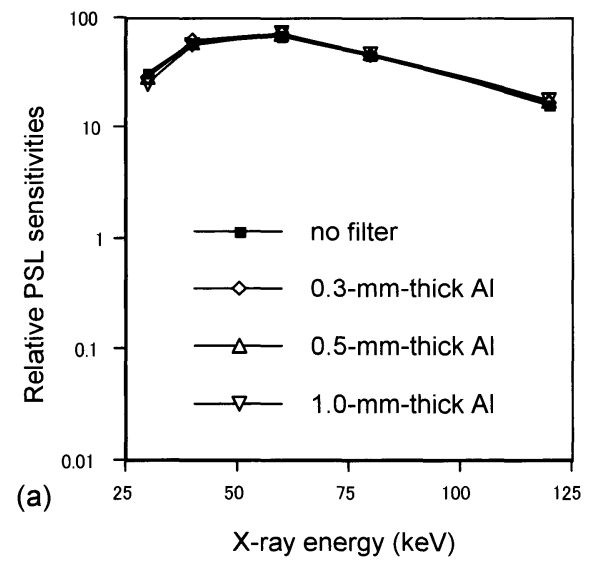

(b)
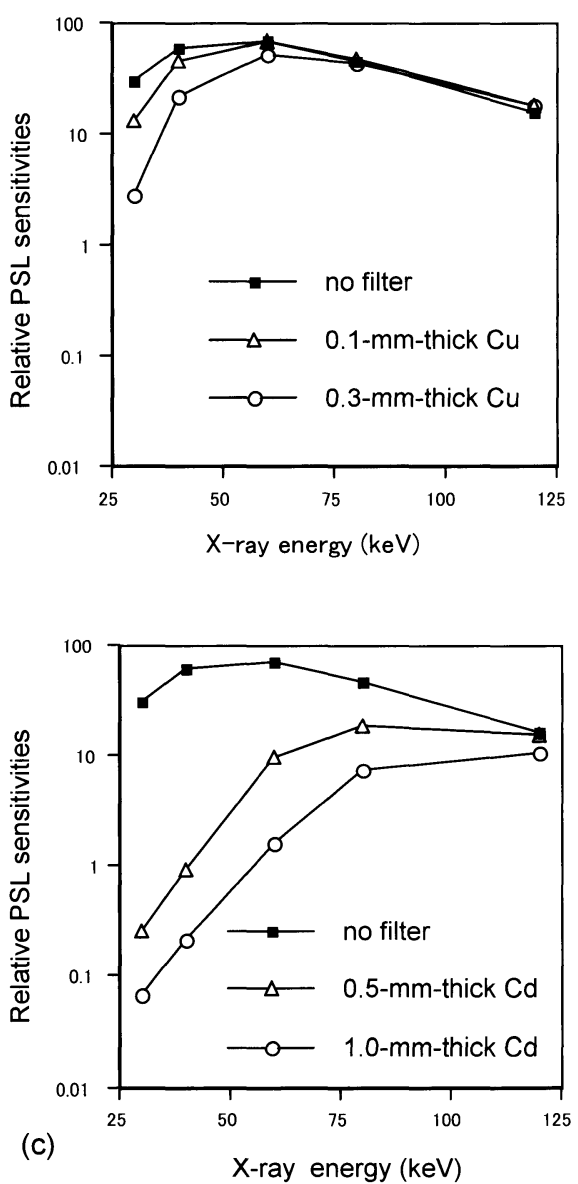

Fig. 2 Relative PSL sensitivities normalized by the sensitivity data measured using ${ }^{137} \mathrm{Cs}$ gamma rays both with and without (a) aluminum, (b) copper, and (c) cadmium filters of different thicknesses.

\section{Results and Discussion}

By combining the sensitivity data measured using 1.0-mm-thick aluminum, 0.1-mm-thick copper, and 0.5-mm-thick cadmium filters in Figs. 2a, 2b and 2c, a constant PSL sensitivity of an imaging plate can be obtained independent of the effective X-ray energy. By taking the weighted sum shown in Equation 1, a response having flat energy dependence can be obtained as shown in Fig. 3,

$$
\operatorname{Res}_{\mathrm{sum}}=1.1 \times \operatorname{Res}_{\mathrm{Al}}-0.94 \times \operatorname{ResCu}_{\mathrm{C}}+0.85 \times \operatorname{Res\mathrm {Cd}}
$$

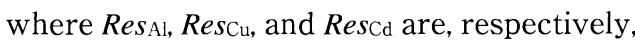
the IP sensitivities measured with 1.0-mm-thick aluminum, 0.1-mm-thick copper, and 0.5-mmthick cadmium filters. All sensitivity data were normalized to the corresponding sensitivity data of the ambient dose equivalent measured using ${ }^{137} \mathrm{Cs}$ gamma rays.

Figure 3 shows that the IP sensitivity so obtained was constant to relative PSL sensitivities of 11.025 within $\pm 4 \%$ variation for $\mathrm{X}$-rays with effective energies less than $80 \mathrm{keV}$. Using the flat ambient dose equivalent response, the values of $H^{*}(10)$ of scattered photons for a specific period were obtained as shown in Equation 2 ,

$$
\begin{aligned}
H= & \operatorname{Res} \text { sum } / 11.025 \times\left(P S L / \mathrm{mm}^{2}\right)_{15}{ }_{15} \mathrm{C}, 24 \mathrm{~h} / \\
& \left(P S L / \mathrm{mm}^{2}\right)_{80}{ }^{\circ} \mathrm{C}, 24 \mathrm{~h}
\end{aligned}
$$

where $H$ is the ambient dose equivalent, $R e s_{\text {sum }}$ is the sum obtained from Equation 1 using each PSL density $\left(P S L / \mathrm{mm}^{2}\right)$ after $80{ }^{\circ} \mathrm{C}$ for $24 \mathrm{~h}$ annealing, and $\left(P S L / \mathrm{mm}^{2}\right)_{15}{ }^{\circ} \mathrm{C}, 24 \mathrm{~h} /(P S L /$ $\left.\mathrm{mm}^{2}\right)_{80^{\circ} \mathrm{C}, 24 \mathrm{~h}}$ is the ratio of PSL densities between $15{ }^{\circ} \mathrm{C}$ for $24 \mathrm{~h}$ and $80{ }^{\circ} \mathrm{C}$ for $24 \mathrm{~h}$. The ratio was estimated to be 20.37 by irradiating an IP sheet with $20 \mathrm{mGy} X$-ray.

The values of $H^{*}(10)$ of scattered photons were thus evaluated at several measuring 


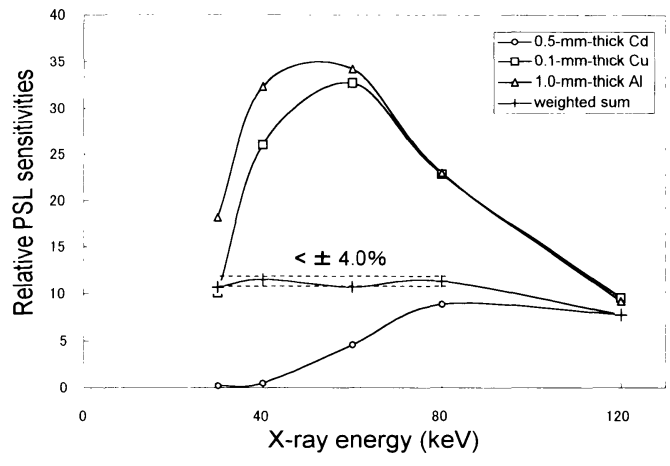

Fig. 3 Relative PSL sensitivities normalized by the sensitivity data measured using ${ }^{137} \mathrm{Cs}$ gamma rays with 1.0-mm-thick aluminum, 0.1-mmthick copper, and 0.5-mm-thick cadmium filters. The + symbols indicate the weighted sum of relative PSL sensitivities of the combined sensitivity data from the three different metal filters.

points both inside and outside a diagnostic Xray room in Fig. 1 and are also listed in Table 1.

In Table 1 , the numbers of interventional cardiology procedures performed in the diagnostic X-ray room were 38,53 , and 22 cases during the periods $3-29$ July 2004, 30 July -2 September 2004, 3 - 15 September 2004, and 24 September -8 October 2004, respectively. Values of $H^{*}(10)$ at points 1 and 4 increased according to the numbers of IR procedures performed. At point 1, the values of $H^{*}(10)$ were rather low compared with results at other points for all periods, as the IP was placed on the reverse side of the lead shield against the $\mathrm{X}$ ray tube. The value at point 7 , where the IP was placed on the surface of a monitor screen, was rather high. At this point the X-ray beams might hit the monitor directly without being scattered by surrounding materials. When comparing results at point 2 under the couch with those at point 3 right above the couch for the same period (3-15 September 2004), the value of $H^{*}(10)$ at point 2 was about seven
Table 1 Values of the ambient dose equivalents $H^{*}(10)$ in the diagnostic X-ray room.

Measuring point numbers correspond to those appeared in Fig.1

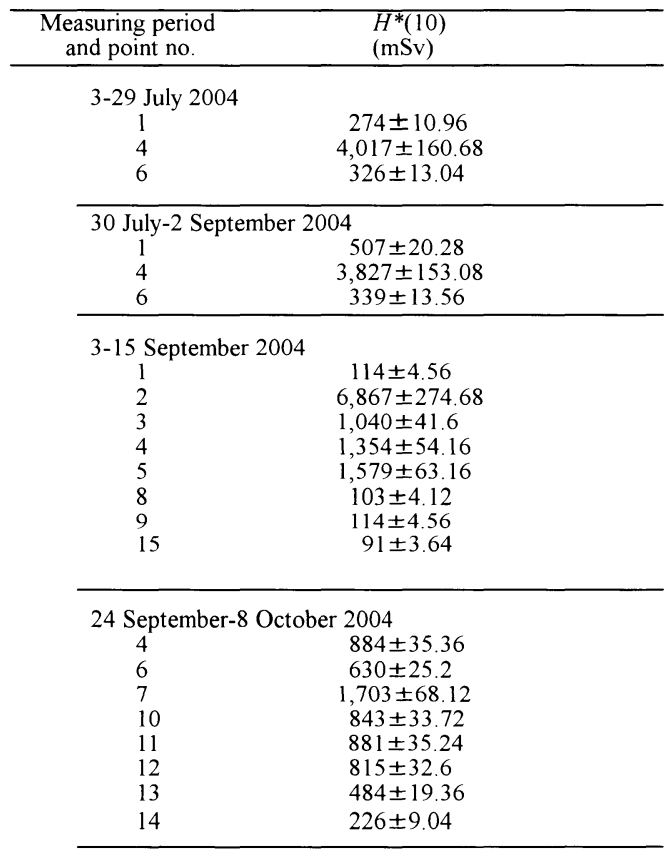

times that at point 3 . Points 4 and 5 were on the surface of the same wall at different heights of $265 \mathrm{~cm}$ and $150 \mathrm{~cm}$, respectively. The values of $H^{*}(10)$ at point 5 was higher than those at point 4. At points 5,6 , and $8-15$, IPs were placed at the same height of $150 \mathrm{~cm}$ above the floor. The values of $H^{*}(10)$ varied significantly according to the distance between the X-ray tube and the measurement point. At point 15 outside the room for the period 3-15 September 2004, a minimum $H^{*}(10)$ value of $91 \mathrm{mSv}$ was observed. The values of $H^{*}(10)$ could vary largely according to the place in a diagnostic Xray room. Authors showed that the detection limit and the upper limit of dynamic range of BAS-MS using the annealed IPs method were $3.15 \mu \mathrm{Gy}$ for ${ }^{137} \mathrm{Cs}$ gamma rays ${ }^{11}$ and approximately $10 \mathrm{~Gy}$ for X-rays". This wide dynamic range of seven orders of magnitude by using 
the annealed IPs method can sufficiently cover the range of the values of $H^{*}(10)$ in a diagnostic X-ray room, as shown in Table 1.

A practical application to area monitoring inside diagnostic radiology rooms involves placing a small, inexpensive, passive dosimeter such as an IP that can be left unattended for a specific period and then easily exchanged and evaluated. Explicit knowledge of the effective $\mathrm{X}$-ray energy is required when evaluating ambient dose equivalents or personal dose equivalents using dosimeters like IPs having strong energy dependence. However, estimating the effective energies of scattered photon radiation is difficult and troublesome in practice. The comprehensive result in this study showed that the method using the flat ambient dose equivalent response with IPs and the annealing technique can be used to estimate values of $H^{*}(10)$ in this energy range and in a wide dynamic range in the representative diagnostic X-ray room, practically.

\section{References}

1) International Commission on Radiological Protection (ICRP), Avoidance of radiation injuries from medical interventional procedures, ICRP Publication 85, (Ann.ICRP , 30 (2)) Oxford : Pergamon Press (2000)

2) Vano, E., Arranz, L., Sastre, J.M., Moro, C., Ledo, A., Garate, M.T. and Minguez, I., Dosimetric and radiation protection considerations based on some cases of patient skin injuries in interventional cardiology, Br. J. Radiol., 71, 510-516 (1998)

3) Faulkner, K. and Vano, E., Deterministic effects in interventional radiology, Radiat. Prot. Dosim., 94, 95-98 (2001)

4) Ohuchi, H., Yamadera, A. and Baba, M., Development of a new passive integral dosimeter for gamma ray monitoring using an imaging plate, Radiat. Prot. Dosim., 107, 239-246 (2003)

5) Ohuchi, H., Yamadera, A. and Baba, M., A new passive dosemeter using an imaging plate and annealing, RADIOISOTOPES, 53, 115-122 (2004)

6) Ohuchi, H. and Yamadera, A., Development of a functional equation to correct fading in imaging plates, Radiat. Meas., 35, 135-142 (2002)

7) Ohuchi, H. and Yamadera, A., Application of an Imaging Plate to a dosemeter for high gamma and X-ray radiation fields, Jpn. J. Healthl Phys., 39, 198-205 (2004) (in Japanese) 